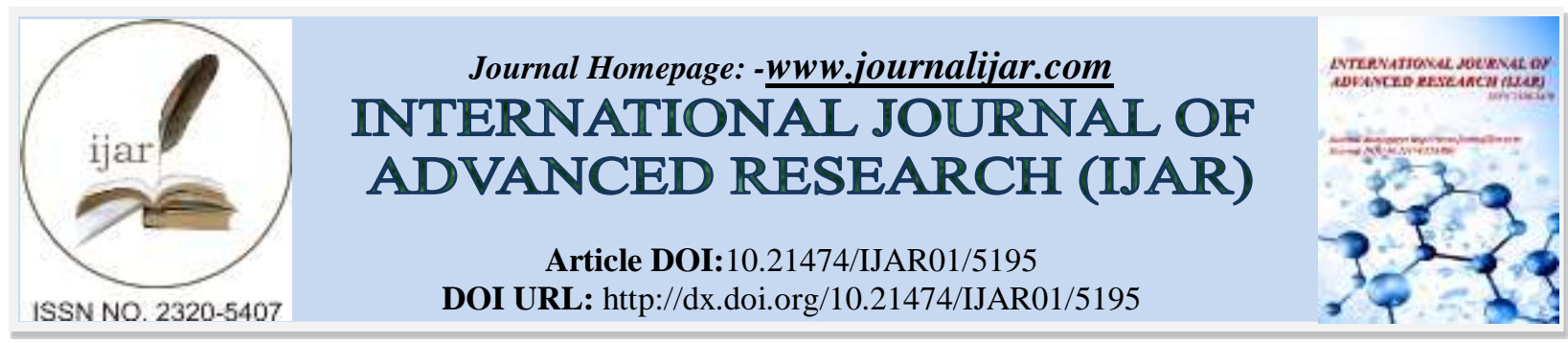

RESEARCH ARTICLE

\title{
INDOOR AIR POLLUTION AND TREATMENT OUTCOMES IN TB PATIENTS OF A HIILY DISTRICT IN NORTH INDIA.
}

\section{Harshvardhan Singh, Anita Thakur, Salig Ram Mazta, Tripti Chauhan and Shishupal Singh Thakur.}

\section{Manuscript Info}

(.........................

Manuscript History

Received: 17 June 2017

Final Accepted: 19 July 2017

Published: August 2017

Keywords:-

Tuberculosis, Treatment outcomes,

Indoor air pollution.

\section{Abstract}

Background: India carries the highest burden of Tuberculosis in the world. For progression towards the goal of global elimination, it is imperative to understand the factors which influence the treatment outcomes. The objectives were to study the socio-demographic characteristics of the subjects and to study the factors influencing treatment outcomes in the TB patients.

Methods: A Cross-sectional study design was employed and all patients $(n=117)$ who were registered for Category I DOTS during the last quarter of 2015 were included after obtaining written informed consent. Patients were visited at their homes for interviews to note socio-demographic and environmental characteristics and secondary data analysis was done to note the outcomes. Univariate and binary logistic regression models were employed.

Results: The overall treatment success rate was $93.2 \%$ (Cure rate= $87 \%$, treatment completion rate $=100 \%$ ). Default, death, failure and lost to follow up rates were $2.6 \%, 2.6 \%, 0.8 \%$ and $0.8 \%$ respectively. Those with a history of indoor air pollution [OR: 7.89 (1.10-62.13); $\mathrm{p}=0.02]$, tobacco smoking [OR: 6 (1.27-28.37); $\mathrm{p}=0.02$ ], alcohol use [OR: 6.13 (1.57-23.93); $\mathrm{p}=0.01$ ] and second hand smoke [OR: 8.75 (1.11-68.88); $\mathrm{p}=0.02$ ] had higher odds of developing unfavourable treatment outcomes. The commonest cause of indoor air pollution was smoke surfacing out of fire-wood used for cooking and tobacco.

Conclusion: The study observed air pollution due to firewood and tobacco smoke and alcohol intake to be associated with adverse outcomes. Health education regarding the ill effects of indoor air pollution and alcohol with regards to the disease preventability and curability needs to be further intensified. Larger studies are highly recommended to determine the effect of indoor air pollution as a risk factor and its impact on treatment outcomes by contemporary scientific methods.

Copy Right, IJAR, 2017,. All rights reserved.

\section{Introduction:-}

Worldwide in 2015, there were an estimated 10.4 million incident TB cases. India is now the country with the highest burden of TB disease in the world and the rate of its progress in TB control will have a major influence on whether the global milestones are achieved. ${ }^{1}$ 
Complete cure is the most desirable outcome for an individual suffering from a disease whereas continued or recurrent morbidity, disability and mortality are the un-favourable outcomes which limit the effectiveness of treatment or a health programme. Various factors are known to influence the treatment outcomes of a disease in varying socio-demographic conditions and these need to be studied extensively for planning improvements in various components of the health care delivery system.

Historically, TB has been used as a prime example of a "social disease", the control of which requires social, economic and environmental interventions. ${ }^{2}$ Household air pollution (HAP) is usually measured indoors, and arises from domestic activities of cooking, heating, and lighting, particularly in low and middle income countries (LMICs). Respiratory infections (comprising both upper and lower respiratory tract infections with viruses, bacteria, and mycobacteria) have all been associated with exposure to household air pollution. ${ }^{3}$

Shimla is the third most populous district of Himachal Pradesh (out of 12), after Kangra and Mandi with a population of 0.8 million out of the total state's population of about 7 million. As per the 2011 census, the aggregate male and female literacy rates were $95.75 \%$ and $93.35 \%$ respectively. ${ }^{4}$ In $2015,13,932$ new cases of Tuberculosis were registered in the state out of which 1267 were registered in district Shimla. ${ }^{5}$

Understanding the local epidemiology will help in formulating appropriate control strategies at the basic level. Hence, the present study was undertaken with the objectives of studying the socio-demographic profile of patients, the magnitude and determinants of treatment outcomes of TB among the patients registered under RNTCP.

\section{Materials \& Methods:-}

A Cross-sectional study design was employed and the Tuberculosis patients initiated on Category I DOTS in the fourth quarter of 2015 who gave informed consent/assent at the included Tuberculosis units were enrolled for the study. The cases already diagnosed with Immuno-deficiency disorders or on corticosteroids were excluded.

Assuming a two-sided significance level of $95 \%$ and a power of $80 \%$; assuming the percentage of un-exposed with favourable outcomes to be $90 \%$ and of exposed with favourable outcomes to be $80 \%$ and non-response rate of $10 \%$, the sample size was calculated to be 117. Considering the average registration of Category I treatment in the previous year, two Tuberculosis units were enrolled for study out of the eight TUs by simple random sampling.

Primary data on various attributes was collected during house visits in the included Tuberculosis units. Secondary data was collected from the records of the TUs during scheduled follow-up till the treatment outcomes appeared. A predesigned, pretested, semi-structured schedule was used.

After obtaining necessary approval from the Institutional Protocol Committee, The District Tuberculosis Officer and concerned authorities, the characteristics of individual patients were observed while no reinforcement was given. The patients were managed as per the programme protocol. The factors related to treatment outcomes as per the WHO were studied in each patient in detail as per the predetermined outcome and explanatory variables.

The data was double entered into Epidata and analysed using Epi Info 7 software. Qualitative data was expressed in percentages with 95\% confidence intervals. Quantitative data was expressed in Mean \pm Standard deviation (SD). Chi-square / Fisher's Exact test was used for qualitative variables. Odds' Ratios (OR) with 95\% Confidence intervals (CIs) were calculated as the measures of association. Variables found to be statistically significant in bivariate analysis were included in a multivariate model while the level of significance was set at $5 \%$.

\section{Results:-}

The present study has observed an almost equal male: female ratio i.e 1.06:1 while the maximum proportion of cases were from the 20-39 age group (48.7\%). The treatment success rate was $93.2 \% ; 95 \%$ CI (88.6 - 97.8\%). $0.9 \%$ were declared as failure. The default rate was $2.6 \%$; $95 \%$ CI $(0.3-5.5 \%)$ and the death rate was $2.6 \%$; $95 \%$ CI $(0.3-$ $5.5 \%)$. The Cure rate among NSP patients was recorded to be $87 \%(78-96 \%)$ and treatment completion rate was $100 \%$ among the NSP and EPTB cases. The maximum treatment success was achieved in the 20-39 years age group (96.5\%) which had a $3.5 \%$ default rate while the maximum death rate was observed in the $\geq 60$-year age group. Maximum success rates were observed in the student group (100\%) while maximum default $(7.7 \%)$ and death rates (7.7\%) were observed in the illiterate group. Higher treatment success rates were observed in those living in nuclear 
families (96.6\%) and in those who were unmarried (97.8\%). The present study has observed excellent adherence rates. $2.6 \%$ missed $33.3 \%$ of their due doses and the most common reason was achieving a symptom free status or feeling better. The present study has found the prevalence of tobacco smoking among the TB patients to be $33.3 \%$ ( $95 \% \mathrm{CI}=24.76 \%$ to $41.84 \%$ ). While $39(66 \%)$ of the males were current smokers and three were quitters $(5 \%)$, only one out of the 58 females was a smoker (1.7\%).

Those exposed to indoor air pollution (47\%) had higher odds of developing adverse outcomes [OR: 7.89 (1.10 62.13); $\mathrm{p}=0.02]$ as were those who were exposed to second hand smoke as compared to those who were not [OR: $8.75(1.11-68.88) ; p=0.02$ ]. Higher odds of adverse outcomes were observed in those with a history of tobacco smoking [84.6\%; OR: $6(1.27-28.37) \mathrm{p}=0.02$ ] and in those with a history of alcohol use [80\%; OR: 6.13 (1.57 23.93); $\mathrm{p}=0.01]$.

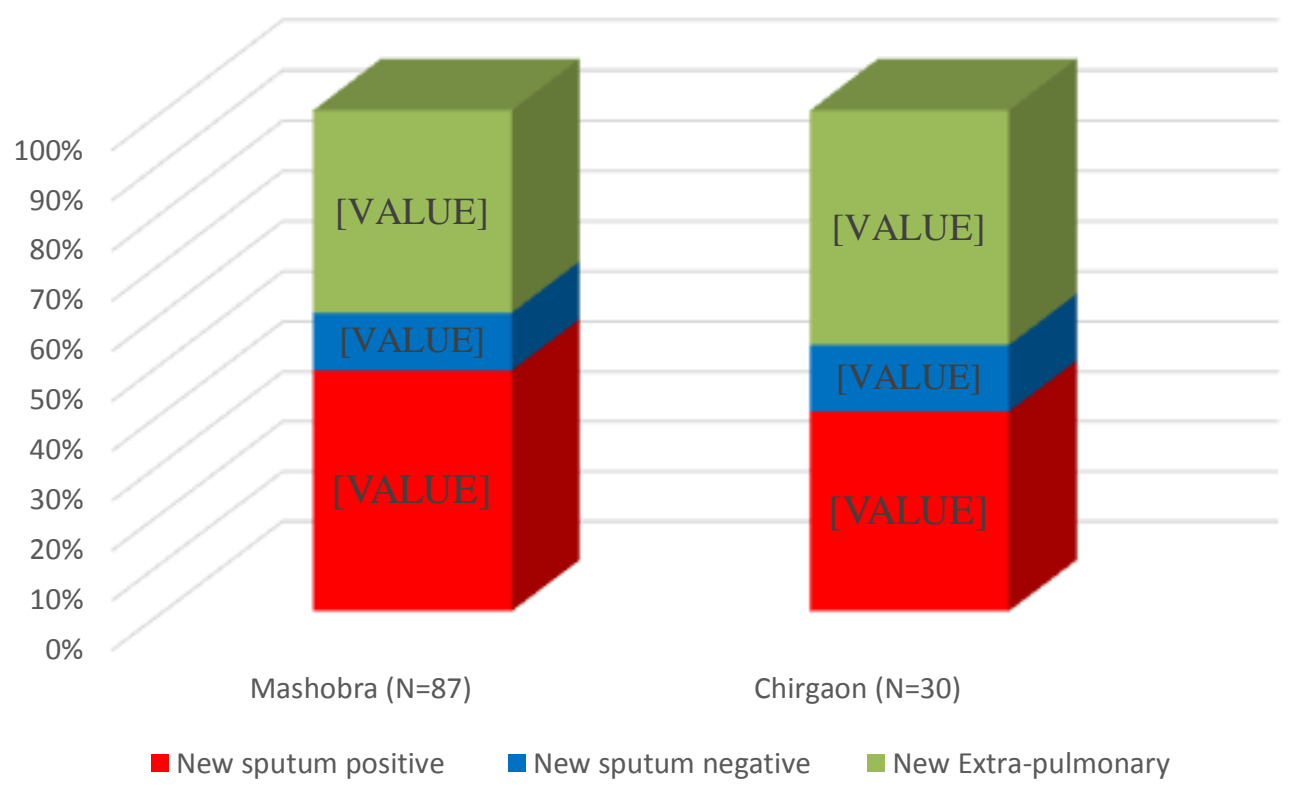

Figure I:-Distribution of study subjects (n) by category of TB at the two Tuberculosis units.

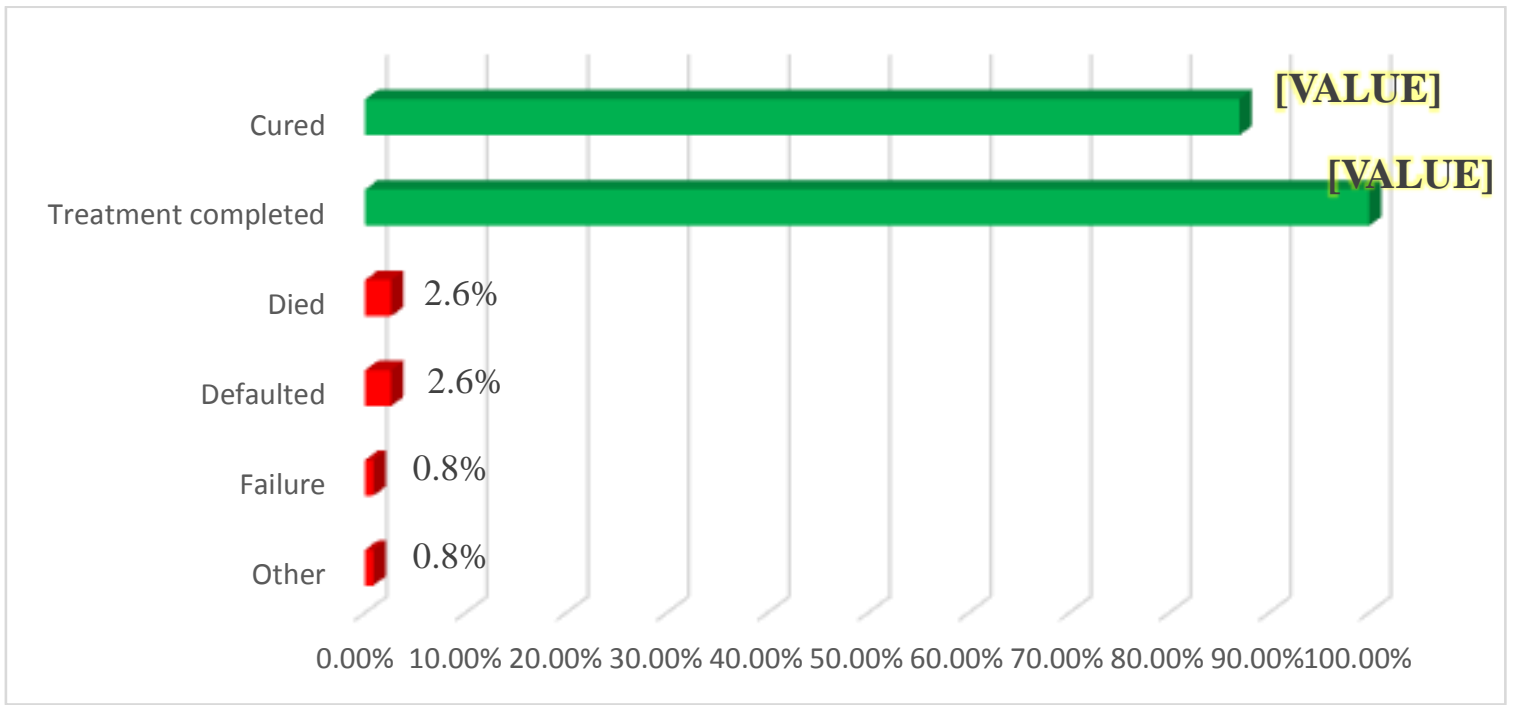

Figure II:-Treatment outcomes among new drug susceptible Tuberculosis patients on Category I DOTS at TUs Mashobra and Chirgaon registered during October- December, 2015 ( $\mathrm{n}=117)$. 


\begin{tabular}{|c|c|c|c|c|}
\hline Characteristics & $\begin{array}{c}\text { Adverse outcome* } \\
\text { N (\%) }\end{array}$ & $\begin{array}{c}\text { Favourable outcome } \\
{ }^{t} \mathbf{N}(\%)\end{array}$ & $\begin{array}{c}\text { Odds Ratio } \\
\text { (95\% CI) }\end{array}$ & p value \\
\hline \multicolumn{5}{|c|}{ Total patients $(\mathrm{n}=117)$} \\
\hline \multicolumn{5}{|l|}{ Sex } \\
\hline Male & $6(10.2)$ & $53(89.8)$ & $2.9(0.62-14.02)$ & \multirow[t]{2}{*}{0.17} \\
\hline Female & $2(3.5)$ & $56(96.5)$ & 1 & \\
\hline \multicolumn{5}{|l|}{ Age groups } \\
\hline$\geq 40$ & $5(10.9)$ & $41(89.1)$ & $2.57(0.64-10.25)$ & \multirow[t]{2}{*}{0.19} \\
\hline$<40$ & $3(4.2)$ & $68(95.8)$ & 1 & \\
\hline \multicolumn{5}{|l|}{ Type of TB } \\
\hline $\begin{array}{l}\text { Bacteriologically } \\
\text { confirmed TB }\end{array}$ & $6(11.2)$ & $48(88.8)$ & $6.89(0.86-55.43)$ & 0.05 \\
\hline $\begin{array}{l}\text { Clinically diagnosed } \\
\text { TB }\end{array}$ & $2(3.2)$ & $61(96.8)$ & 1 & \\
\hline \multicolumn{5}{|c|}{ Smoking tobacco status } \\
\hline Smokers & $6(15.4)$ & $33(84.6)$ & $6.0(1.27-28.36)$ & \multirow[t]{2}{*}{ 0.02* } \\
\hline Non-smokers & $2(2.6)$ & $76(97.4)$ & 1 & \\
\hline \multicolumn{5}{|c|}{ Second hand smoke exposure } \\
\hline Present & $7(13.5)$ & $45(86.5)$ & $8.75(1.11$ - 68.87) & 0.01* \\
\hline Absent & $1(1.5)$ & 64 (98.5) & 1 & \\
\hline \multicolumn{5}{|l|}{ Indoor air pollution } \\
\hline Present & $7(12.8)$ & $48(87.2)$ & $7.89(1.10-62.13)$ & 0.02* \\
\hline Absent & $1(1.6)$ & $61(98.4)$ & 1 & \\
\hline \multicolumn{5}{|l|}{ Alcohol use } \\
\hline Present & $5(20)$ & $20(80)$ & $6.13(1.57-23.93)$ & 0.01* \\
\hline Absent & $3(3.3)$ & $89(96.7)$ & 1 & \\
\hline
\end{tabular}

Table 1:- Associations between ADVERSE TREATMENT OUTCOMES and socio-demographic \& clinical characteristics among new Drug- susceptible TB patients.

\section{Discussion:-}

Among the 117 patients studied, an almost equal male: female ratio i.e 1.06:1 was observed. Male to female ratio of TB cases reported to the WHO is around 1.5-2.1 in all regions of the world (WHO 2000). TB prevalence is significantly higher among men than women in low- and middle-income countries. ${ }^{7}$

Various international and Indian studies have found positive associations between overcrowding and poor ventilation with higher prevalence of TB. ${ }^{8,9,10,11}$ In the present study, a considerable number of patients were exposed to inadequate ventilation [54(46.1\%)] while Overcrowding was not observed in the majority of the patients $[6(5.1 \%)]$.

3 billion people worldwide are exposed to toxic amounts of household air pollution every day because they use solid fuels, a term that includes biomass fuels (derived from plant sources) or coal for combustion resulting in the release of products of incomplete combustion such as carbon monoxide and particulate matter (PM). Furthermore, solid fuel is commonly used in homes with poor or absent chimney ventilation of smoke. In extreme climates (e.g. Nepal and north India), ventilation is deliberately minimised to conserve energy, resulting in extremely toxic amounts of HAP for a substantial proportion of the year. ${ }^{3}$ Indoor air pollution arising as a result of firewood smoke emissions from household "chullahs" has been recognised as an independent risk factor for TB in various studies. ${ }^{12,13}$ The present study has found second hand tobacco smoke exposure to be present in $44.8 \%$ of the patients and exposure to indoor air pollution in $47 \%$ of the households which was mostly due to indoor tobacco smoking and use of firewood and kerosene for cooking and heating and absence/inadequate use of chimneys or vents was also observed. Household air pollution use is an important risk factor for TB, especially among adult women who are primary cooks in India using biomass fuel for cooking and are also exposed to tobacco smoke. ${ }^{14}$ This study has also found the proportion of housewives to be high $(60.3 \%)$ indicating a higher susceptibility of acquiring the infection. Poorer outcomes have been observed in the present study among the patients exposed to indoor air pollution, tobacco smoking and alcohol. A very recent Indian study has also found indoor air pollution to be independently associated with adverse TB treatment outcomes [AOR: $3.66(1.46-9.18) ; p=0.006$ ] ${ }^{15}$ 
Tuberculosis and tobacco smoking are both global public health threats. Innumerable studies have established significant associations between tobacco smoking, prevalence of TB and adverse outcomes ${ }^{16,17,18}$ and have concluded that smoking roughly doubles the risk of tuberculous infection, active TB disease and death. ${ }^{19}$ The present study has found the prevalence of tobacco smoking among the TB patients to be $33.3 \%$ (95\% CI= 24.76\% to $41.84 \%)$. The trends of smoking observed despite a nation-wide campaign and legislations indicate towards a hard to change social behaviour. The results indicate that the knowledge about the ill effects of second hand smoke and indoor air pollution is still a grey area in TB control and need to be further explored.

Prevalence of alcohol use disorders among TB patients have ranged from $10 \%$ to $50 \%$ as per various international $^{20,21}$ and a recent Indian study. ${ }^{22}$ The present study has observed a prevalence of alcohol use among TB patients to be $20.5 \%$ (95\% CI $=13.18 \%$ to $27.82 \%$ ) and all of them were males. However, no significant associated was noted between alcohol use and the type of TB.

Highest treatment success rates were achieved in the new sputum negative patients (100\%) followed by extrapulmonary (95.8\%) and new sputum positive patients (87\%).

The results are concordant with the global priority indicators and targets for monitoring the implementation of the End TB Strategy (2015-2025) which have set the target of achieving $90 \%$ treatment success rate. ${ }^{6}$

The present study has observed excellent adherence rates. $2.6 \%$ missed $33.3 \%$ of their due doses and the most common reason was achieving a symptom free status or feeling better. A study conducted outside India established that $29.8 \%$ of TB patients failed to comply with TB drug taking regimen once they started feeling better ${ }^{23}$ Excellent adherence rates ultimately leading to successful treatment outcomes can be attributed to the self-motivation of patients complemented by regular follow-up by the programme staff.

No significant difference was observed in the patients experiencing different adverse effects. Side effects had no direct bearing on treatment outcomes, indicating that minor side effects were taken care of and adherence was maintained. Self-motivation of the patients complemented by the effective education and communication may be the most likely reasons for achieving favourable outcomes.

\section{Conclusions:-}

The study observed air pollution due to firewood and tobacco smoke and alcohol intake to be associated with adverse outcomes. Health education regarding the ill effects of indoor air pollution and alcohol with regards to the disease preventability and curability needs to be further intensified. Larger studies are highly recommended to determine the effect of indoor air pollution as a risk factor and its impact on treatment outcomes by contemporary scientific methods.

\section{References:-}

1. TB India 2016. Annual status report. New Delhi: Central TB division, Directorate General of Health Services, Ministry of Health and Family Welfare, Govt. of India; 2016: 9.

2. Lönnroth K, Jaramillo E, Brian G. Williams, Christopher Dye and Raviglione M. Drivers of tuberculosis epidemics: The role of risk factors and social determinants, Social Science \& Medicine; 2009: 41-9.

3. Respiratory risks from household air pollution in low and middle income countries. Lancet Respir Med 2014; 2 : 823-60.

4. Himachal Pradesh Government. Official website of district Shimla administration. Available from: http://hpshimla.nic.in/sml_fact.htm

5. Government of Himachal Pradesh. Department of Health \& Family welfare. Office of the State Tuberculosis Officer.

6. World Health Organisation. End TB Strategy. Global strategy and targets for tuberculosis prevention, care and control after 2015. Available from: http://www.who.int/tb/post2015_strategy/en/

7. Horton KC, MacPherson P, Houben RMGJ, White RG and Corbett EL. Sex Differences in Tuberculosis Burden and Notifications in Low- and Middle-Income Countries: A Systematic Review and Meta-analysis. PLoS Med 2016. 13(9): e1002119.

8. Narasimhan P, Wood J, MacIntyre CR and Mathai D. Risk Factors for Tuberculosis. Pulmonary Medicine 2013; 828939: 1-10. 
9. Jose I Figueroa-Munoz and Pilar Ramon-Pardo. Tuberculosis control in vulnerable groups. Bulletin of the World Health Organization. Available from: http://www.who.int/bulletin/volumes/86/9/06-038737/en/

10. Drucker E, Alcabes P, Bosworth W and Schell B. Childhood tuberculosis in the Bronx, New York, The Lancet. 1994; 343: 1482-1485.

11. Dhanaraj B, Papanna MK, Adinarayanan S, Vedachalam C, Sundaram V, Shanmugam S, et al. Prevalence and Risk Factors for Adult Pulmonary Tuberculosis in a Metropolitan City of South India. PLoS ONE 2015; 10(4): e0124260.

12. Wood R. Contact with infectious adults, poor ventilation raised risk for TB in young children. Clin Infect Dis 2010; 51: 401-8.

13. Lakshmi PV, Virdi NK, Thakur JS, Smith KR, Bates MN and Kumar R. Biomass fuel and risk of tuberculosis: a case-control study from Northern India. J Epidemiol Community Health.2012; 66 (5):457-61.

14. Sehgal M, Rizwan SA, Krishnan A. Disease burden due to biomass cooking-fuel-related household air pollution among women in India. Global Health Action. 2014;7:10.3402/gha.v7.25326. doi:10.3402/gha.v7.25326.

15. Mundra A. Magnitude and determinants of adverse Treatment outcome among tuberculosis patients Treated under revised national tuberculosis Control programme in a tuberculosis unit. J Epidemiol Global Health. 2017; 7 (2):111-8.

16. Wang J, Shen H. Review of cigarette smoking and tuberculosis in China: intervention is needed for smoking cessation among tuberculosis patients. BMC Public Health 2009; 9: 292.

17. Kanakia KP, Majella MG, Thekkur P, Ramaswamy G, Nair D and Chinnakali P. Osong Public Health Res Perspect 2016; 7(4): 228-32.

18. Bates MN, Khalakdina A, Pai M, Chang L, Lessa F, Smith K R. Risk of tuberculosis from exposure to tobacco smoke: a systematic review and meta-analysis. Arch Intern Med 2007; 167: 335-42.

19. Lin H H, Ezzati M, Murray M. Tobacco smoke, indoor air pollution and tuberculosis: a systematic review and meta-analysis. PLOS Med 2007; 4: e20.

20. Lönnroth K, Williams BG, Stadlin S, Jaramillo and Dye C. Alcohol use as a risk factor for tuberculosis - a systematic review. BMC Public Health 2008; 8: 289.

21. Volkmann T, Moonan PK, Miramontes R and Oeltmann JE. Tuberculosis and excess alcohol use in the United States, 1997-2012. Int J Tuberc Lung Dis 2013; 19(1): 111-119.

22. Veerakumar AM, Sahu SK, Sarkar S, Kattimani S. Factors affecting treatment outcome among Pulmonary Tuberculosis patients under RNTCP in urban Pondicherry, India. Indian J Comm Health 2016; 28(1): 94 - 99.

23. Nanda GS, Singh H, Sharma B and Arora A. Adverse Reactions Due to Directly Observed Treatment Short Course Therapy: An Indian Prospective Study. IAIM 2016; 3(1): 6-12. 